\title{
Effect of demineralization on the physiochemical structure and thermal degradation of acid treated indigenous rice husk
}

\author{
Umair Aslam ${ }^{1}$, Naveed Ramzan", Tanveer Iqbal' ${ }^{2}$ Mohsin Kazmi², Aamir Ikhlaq \\ ${ }^{1}$ University of Engineering \& Technology, Department of Chemical Engineering, Lahore 54890, Pakistan \\ ${ }^{2}$ University of Engineering and Technology, Department of Chemical Polymer \& Composite Material Engineering, City \\ Campus, Pakistan \\ ${ }^{3}$ University of Engineering and Technology, Institute of Environmental Engineering and Research, Lahore, Pakistan \\ "Corresponding author: e-mail: umairaslam@uet.edu.pk
}

\begin{abstract}
Energy generation from biomass presents some serious problems like slagging, fouling and corrosion of boilers. To address these problems, demineralization of biomass is performed using different leaching agents. This study is focused on determining the influence of leaching agents and leaching time on the physiochemical structure of rice husk during demineralization. Dilute (5\% wt) solutions of $\mathrm{HCl}$ and $\mathrm{H}_{2} \mathrm{SO}_{4}$ were used for the demineralization of rice husk separately with leaching time of 15,60 and 120 minutes. It is shown that $\mathrm{H}_{2} \mathrm{SO}_{4}$ exhibited higher removal of alkali and alkaline earth metals (AAEM) comparatively as depicted by the $34.2 \%$ decrease in ash content along with an increase of $7.10 \%$ in the heating value. The acid has been seen to induce more notable changes in physiochemical structure as depicted by the FTIR spectra and SEM micrographs. The thermal degradation behavior of the demineralized rice husk has also been reported.
\end{abstract}

Keywords: demineralization, leaching agent, physiochemical structure, alkali and alkaline earth metals, thermal degradation.

\section{PRACTICAL APPLICATION}

Due to depletion in fossil fuels reserves, increase in their price, greenhouse effect and environmental pollution, the current challenge to world is to reduce its dependence on fossil fuel by developing sustainable and renewable energy supply. Energy from biomass accounts for the largest renewable energy in the world ${ }^{\mathbf{1}}$. Biomass is a lignocellulosic material mainly consisting of cellulose, hemicellulose, lignin, ash and extractives ${ }^{2}$. One important feature of biomass is that it contains alkali and alkaline earth metals (AAEM) such as potassium, sodium, magnesium, calcium, iron etc. ${ }^{3}$ AAEM are the main inorganic content of biomass. They are generally present less than $1 \%$ and may go up to $15 \%$ depending on the biomass type ${ }^{4}$. High AAEM content in biomass leads to slagging and fouling of heat exchanger in the high temperature conversion system. Slagging and fouling is the deposition of ash on the heat transfer surface forming an insulating layer. This layer reduces the heat transfer as well as causes corrosion and erosion problems. This condition puts the threat on the safe operation of the thermal system and also increases the cost of operation and maintenance. The main contributors in slagging and fouling are potassium and sodium which lower the melting point of ash resulting in ash deposition on heat transfer surface ${ }^{5-7}$.

Demineralization of biomass has demonstrated to be an effective process for reducing the slagging and fouling nature of it by reducing AAEM content and improving its fuel properties for high temperature processes. Leaching agents (water and different acids) are used to demineralize the biomass in different studies, ${ }^{2-11}$. Jiang $2013^{17}$ et al. used deionized water, acetic acid, hydrochloric acid, sulphuric acid, nitric acid and prthophosphoric acid. It was found that sulphuric acid and nitric acid were able to remove more AAEM than other leaching agents. Asadieraghi et al. $2014^{15}$ demineralized palm oil biomasses with sulphuric acid, hypochlorous acid, hydrofluoric acid, nitric acid and hydrochloric acid. Hydrofluoric acid removed more AAEM than other leaching agents. Although water has less adverse effect on the structure of biomass, but it could hardly remove AAEM. High removal efficiency of AAEM was observed when acids were used but they had potential of attacking on acid soluble hydrocarbons present in biomass in the form of cellulose and hemicellulose. Because of this negative impact created by acids, it is necessary to evaluate the physiochemical and structural changes of biomass during demineralization ${ }^{2}, 10,12,13$.

The present study focuses on the changes on physiochemical structure of rice husk after demineralization using different leaching agents as well as its thermal degradation behavior.

\section{EXPERIMENTAL SECTION}

\section{Material}

Rice husk samples were taken from a local farm. The husk samples were washed with distilled water and dried in sunlight before any further treatment. Dilute solution (5 percent weight/volume) of strong acids i.e. Hydrochloric Acid (HCl, 37\%) (Riedel-deHaën) and Sulphuric Acid $\left(\mathrm{H}_{2} \mathrm{SO}_{4}, 99 \%\right)$ (Riedel-deHaën) were used as leaching agents.

\section{Method}

\section{Demineralization process}

The rice husk samples were cut into $2 \mathrm{~mm}$ particle size. The samples were placed in the dilute acid solutions with a solid to liquid weight ratio of 1:15. The mixtures of rice husk and leaching agents were thoroughly mixed with the help of an orbital shaker at $200 \mathrm{rpm}$ for three different leaching time i.e. $15 \mathrm{~min}, 60 \mathrm{~min}$ and $120 \mathrm{~min}$ at room temperature. The treated biomass samples were then washed with deionized water until the $\mathrm{pH}$ value 
approached to neutral. After washing, treated samples were dried in an oven at $80^{\circ} \mathrm{C}$ for $24 \mathrm{~h}$ and then were stored in air tight bags for further analysis. The identification of each sample and actions performed on them are shown in Table 1.

\section{Scanning electron microscopy (SEM)}

In order to investigate leaching efficiency and structural changes, the surface morphology and shape, all samples were observed by SEM (JEOL JSM-6490 LV) operating at low vacuum and $5 \mathrm{kV}$ accelerating voltage. Conductive coating was applied to prepare the samples for analysis.

\section{Fourier transform infrared (FTIR) Spectroscopy}

FTIR spectroscopy was performed using ASTM E1252 in order to observe the structural changes after demineralization of rice husk qualitatively.

\section{Thermogravimetric Analysis}

Thermal degradation behavior was studied based on the thermal behavior of the samples using a Thermogravimetric Analyzer (TGA) SDT Q600 from TA Instruments. $10 \mathrm{mg}$ sample was taken in platinum crucible.
The sample was placed in the furnace of SDT Q600 TA instrument. It was initially heated up to $100^{\circ} \mathrm{C}$ in $\mathrm{N}_{2}$ environment. Then temperature was raised to $500^{\circ} \mathrm{C}$ in $\mathrm{N}_{2}$ environment. At the end, the sample was burned by increasing the temperature to $950^{\circ} \mathrm{C}$ in $\mathrm{O}_{2}$ environment. The heating rate was set at $10^{\circ} \mathrm{C} / \mathrm{min}$.

\section{Ash percentage and heating value}

The ash percentage was calculated by using ASTM 3174 and heating value was calculated by using ASTM D5865.

\section{RESULTS AND DISCUSSION}

\section{SEM}

Figure 1 shows the SEM images of raw and treated rice husk. Raw sample has clear structure and plant epidermis and stomata are not damaged (shown in Fig. 1a). While fuzziness and erosion can be observed in treated samples (shown in Fig. 1b-1g). Raw sample has less porosity than the treated samples especially in case of Figures $1 \mathrm{f}$ (R5) and $1 \mathrm{~g}$ (R6) which means $\mathrm{H}_{2} \mathrm{SO}_{4}$ as leaching agent has more significant effect on biomass

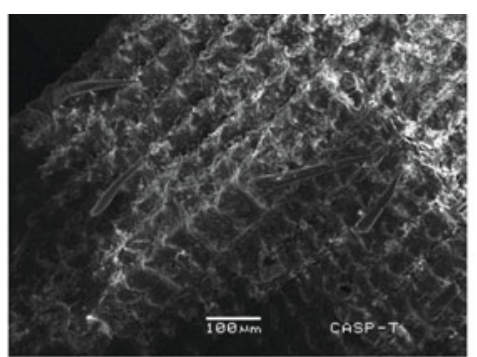

(a) $\mathrm{R}$

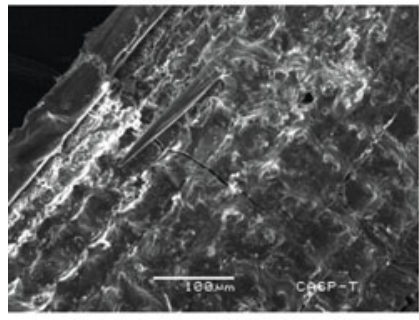

(b) R1

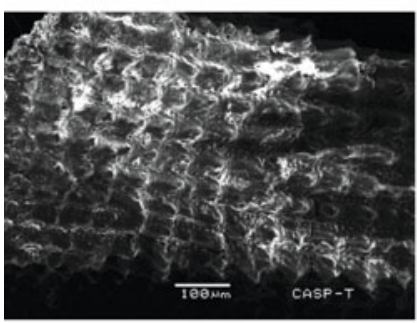

(d) R3

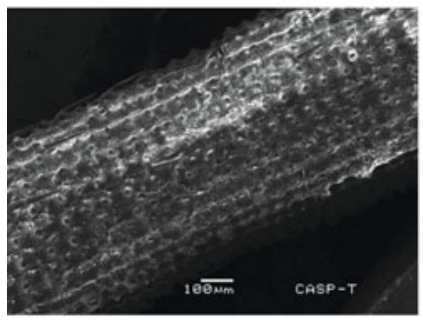

(f) R5

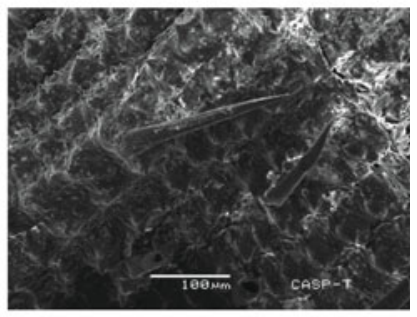

(c) R2

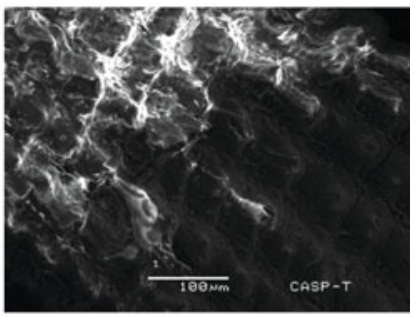

(e) R4

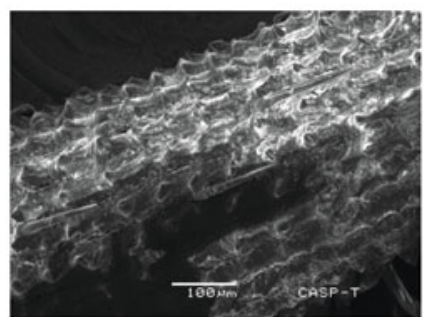

(g) R6

Figure 1. SEM images of raw and treated samples 
Table 1. Identification and actions performed on each sample

\begin{tabular}{|c|c|c|c|}
\hline \multirow[b]{2}{*}{$\begin{array}{l}\text { Sr. } \\
\text { No. }\end{array}$} & \multirow[b]{2}{*}{$\begin{array}{l}\text { Sample } \\
\text { identification }\end{array}$} & \multicolumn{2}{|c|}{ Actions performed } \\
\hline & & $\begin{array}{c}\text { leaching } \\
\text { agent }\end{array}$ & $\begin{array}{l}\text { leaching time } \\
\text { [min] }\end{array}$ \\
\hline 1 & $\mathrm{R}$ & \multicolumn{2}{|c|}{ Raw Rice Husk } \\
\hline 2 & R1 & $\mathrm{HCl}$ & 15 \\
\hline 3 & R2 & - & 60 \\
\hline 4 & R3 & - & 120 \\
\hline 5 & R4 & $\mathrm{H}_{2} \mathrm{SO}_{4}$ & 15 \\
\hline 6 & R5 & - & 60 \\
\hline 7 & R6 & - & 120 \\
\hline
\end{tabular}

structure by dissolving cellulose and hemicellulose ${ }^{11,14}$. Increased porosity also indicates that some material was leached away by dilute acid solutions. The removed particles from biomass might be extractives and minerals ${ }^{15}$. The removal of minerals and extractives and dissolution of hemicellulose and cellulose may result in the higher availability of surface area and pore volume ${ }^{16}$.

\section{FTIR spectroscopy}

Chemical structure evaluation of biomass is frequently studied using infrared spectroscopy. In this study, FTIR technique was used to investigate the impacts of acid treatment on the biomass chemical structure. Figure 2 shows the various FTIR spectra of $\mathrm{HCl}$ (Fig. 2) and $\mathrm{H}_{2} \mathrm{SO}_{4}$ (Fig. 3) treated biomass samples.

In the spectra, the first broad band at $3700-3000 \mathrm{~cm}^{-1}$ can be observed and it is related to $\mathrm{O}-\mathrm{H}$ stretching vibrations of hydroxyl functional groups which may be present in phenolic, alcoholic and carboxylic structures. The band at $2800-3000 \mathrm{~cm}^{-1}$ is attributed to C-H stretching

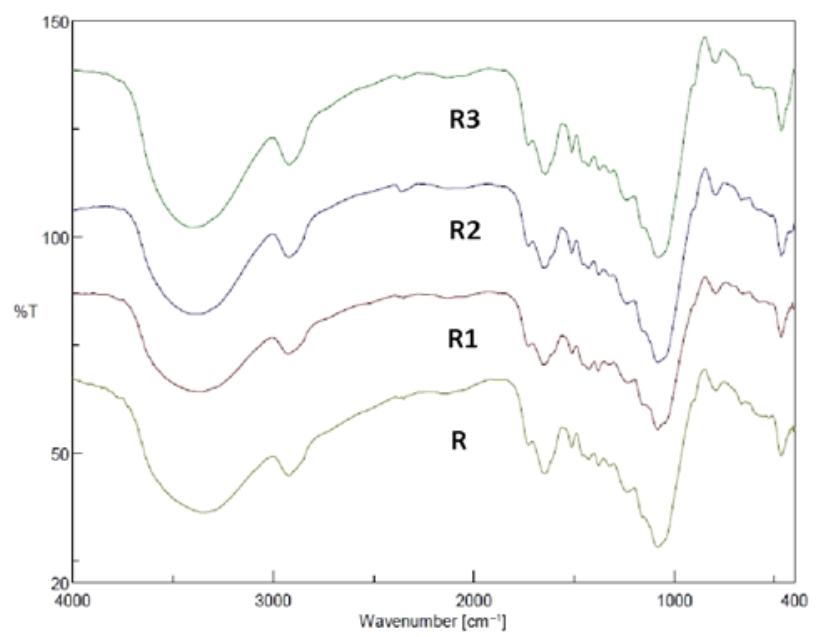

Figure 2. FTIR spectra of raw and $\mathrm{HCl}$ treated samples

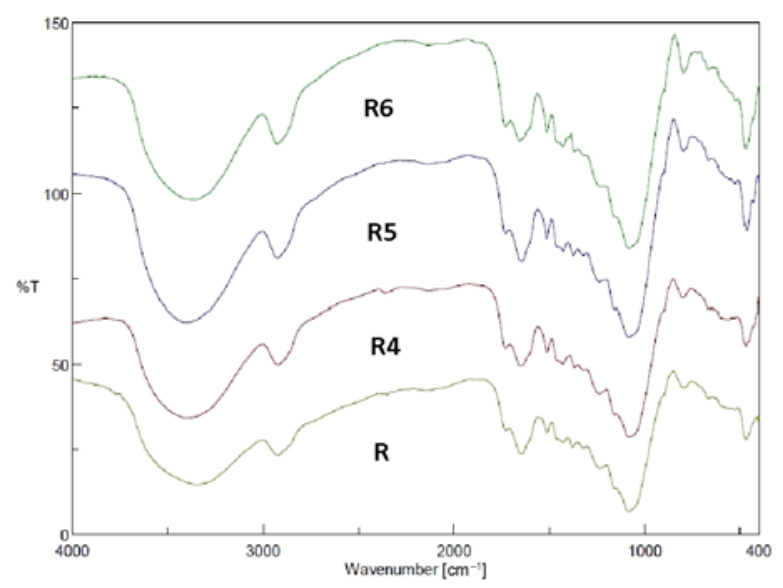

Figure 3. FTIR spectra of raw and $\mathrm{H}_{2} \mathrm{SO}_{4}$ treated samples vibration of $-\mathrm{CH}_{2}$ and $-\mathrm{CH}_{3}$ functional groups. A slight change in both bands can be observed after acid treatment specially for samples R3, R5 and R6 and it is in agreement to with the studies done by Jiang et al. ${ }^{17}$ and Asadieraghi et al. ${ }^{15}$. The peak at $1730 \mathrm{~cm}^{-1}$ corresponds to $\mathrm{C}=\mathrm{O}$ stretching vibration of free carbonyl group therefore it is a typical hemicellulose component. The next peaks from $1650-1510 \mathrm{~cm}^{-1}$ shows $\mathrm{C}=\mathrm{C}$ stretching vibrations of aromatics and generally considered as lignin component. A slight change in intensity of bands around $1730 \mathrm{~cm}^{-1}$ and $1650 \mathrm{~cm}^{-1}$ of samples R3 and R6 can be observed which is probably due to the high removal of inorganics comparatively. The spectrum around 1400-600 $\mathrm{cm}^{-1}$ is very complex to analyze. However, in this region vibrations related to lignin components can be detected as at $1240 \mathrm{~cm}^{-1}(\mathrm{C}=\mathrm{O}$ stretching $), 850-750 \mathrm{~cm}^{-1}(\mathrm{C}-\mathrm{H}$ bending). The band between $1440-1400 \mathrm{~cm}^{-1}$ contains $\mathrm{O}-\mathrm{H}$ bending which are related to hemicellulose and cellulose. A band intensity change in this region can be observed in case of sample R6. All above band variations indicate that some changes have occurred in cross linking between different functional groups and thus represents the acid treatment effects. More significant changes can be observed in case of sample R6.

\section{Thermogravimetric analysis}

Figure 4 shows the TG curves (percentage weight loss vs temperature) and Figure 5 shows DTG curves (differential weight loss vs temperature) for raw and treated samples. Three regions in all the curves can be observed. The first region from $0^{\circ} \mathrm{C}$ to $100^{\circ} \mathrm{C}$ is assigned to water evaporation. The second region between $250-400^{\circ} \mathrm{C}$ is attributed to decomposition of cellulose and hemicellulose. The third region between $450-500^{\circ} \mathrm{C}$ shows the degradation of lignin ${ }^{17}$. In the second region, two peaks can be observed. The first peak represents the decomposition of thermally unstable hemicellulose while second peak is showing the degradation of cellulose. It can also be observed that the peaks of treated samples have slightly shifted towards right side showing an increase in temperature presented in Table 3. This can be explained by the reason that AAEM, which act as catalyst during decomposition, have been removed through acid treatment and cellulose and hemicellulose are now more resistant towards thermal degradation ${ }^{18}$.

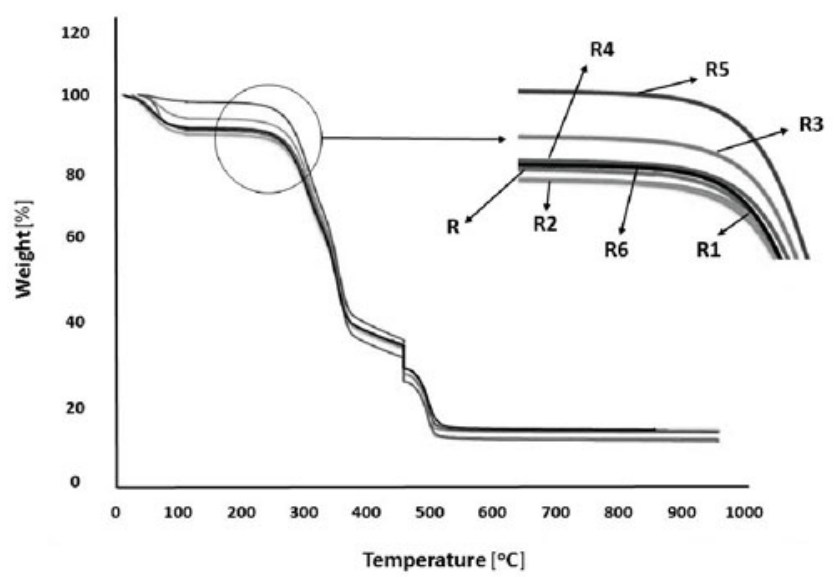

Figure 4. Mass loss (TG) curves of treated and untreated samples 


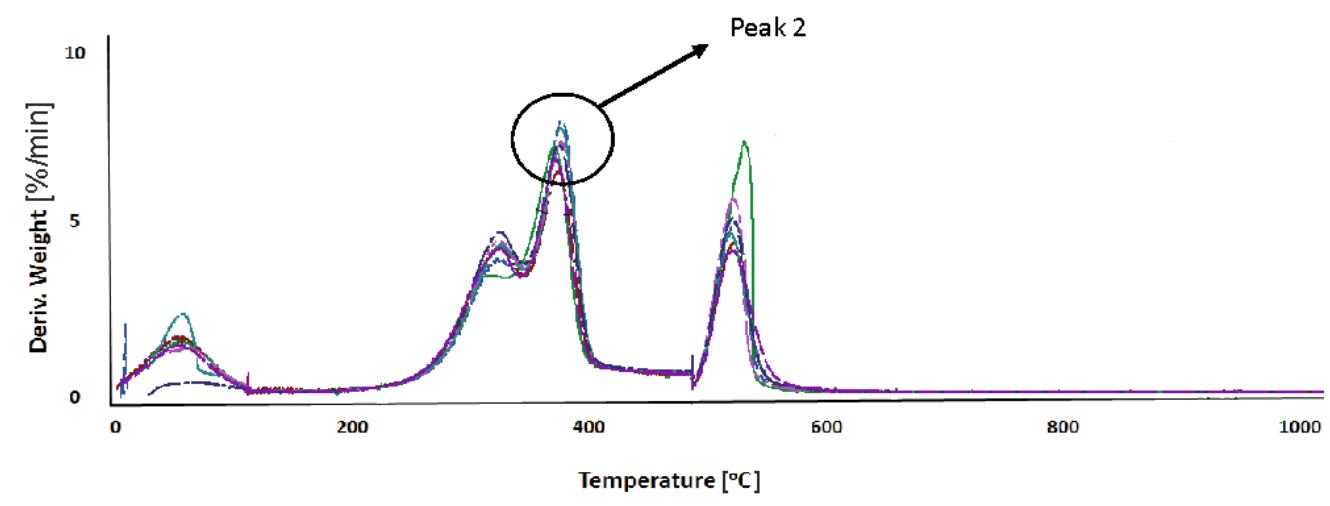

Figure 5. Derivative mass loss (DTG) curves of treated and untreated samples

\section{Ash percentage and heating value}

Table 2 shows the ash percentage and heating value of all the samples. A maximum decrease of $34.2 \%$ in ash content of sample R6 was observed while a maximum increase of $7.10 \%$ in heating value was observed also for R6. These results are consistent with Carrillo et al. ${ }^{\mathbf{1 9}}$. While for R1, R2, R3, R4 and R5 percentage decrease in ash content was 15.6, 17.4, 33, 16.60 and 18.04 respectively and percentage increase in heating value was $0.99,1.53,5.22,0.46$ and 1.72 respectively. As reported for other biomasses a vivid inverse relation between ash content and heating value was observed [e.g., Jenkins et al., 1996]. In addition, it can also be seen from SEM and FTIR of sample R3 and R6 that both leaching agents had more effects comparatively on the physiochemical structures thus complementing the changes in ash content and heating value of the respective samples.

Table 2. Ash content and heating values of untreated and treated samples

\begin{tabular}{|l|c|c|c|}
\hline $\begin{array}{l}\text { Sr. } \\
\text { No. }\end{array}$ & $\begin{array}{c}\text { Sample } \\
\text { identification }\end{array}$ & $\begin{array}{c}\text { Ash content } \\
{[\%]}\end{array}$ & $\begin{array}{c}\text { Heating } \\
\text { value } \\
{[\mathrm{MJ} / \mathrm{kg}]}\end{array}$ \\
\hline 1 & $\mathrm{R}$ & 15.50 & 15.07 \\
\hline 2 & $\mathrm{R} 1$ & 13.08 & 15.22 \\
\hline 3 & $\mathrm{R} 2$ & 12.8 & 15.30 \\
\hline 4 & $\mathrm{R} 3$ & 10.36 & 15.90 \\
\hline 5 & $\mathrm{R} 4$ & 13 & 15.14 \\
\hline 6 & $\mathrm{R} 5$ & 12.7 & 15.33 \\
\hline 7 & $\mathrm{R} 6$ & 10.2 & 16.14 \\
\hline
\end{tabular}

Table 3. Peak 2 temperatures of raw and treated samples

\begin{tabular}{|l|c|c|}
\hline Sr. No. & Sample ID & Temperature of second shoulder $\left[{ }^{\circ} \mathrm{C}\right]$ \\
\hline 1 & R & 345 \\
\hline 2 & R1 & 350 \\
\hline 3 & R2 & 351 \\
\hline 4 & R3 & 355 \\
\hline 5 & R4 & 348 \\
\hline 6 & R5 & 353 \\
\hline 7 & R6 & 355 \\
\hline
\end{tabular}

\section{CONCLUSIONS}

Rice husk is suitable for energy generation but its slagging nature prevents its use at larger scale. In this experimental work, the changes in physiochemical structural of rice husk using different leaching agents and leaching time were studied. The results showed that leaching performed for 2 hours with $\mathrm{H}_{2} \mathrm{SO}_{4}$ have removed more AAEM as revealed by the ash content (34.2\% decrease) comparatively but it also has affected the structure more as depicted by SEM and FTIR. The shifting of peaks of treated samples towards high temperature in TG and DTG curves showed that treated sample are more resistant towards thermal degradation due to the elimination of catalytic role of AAEM. An increase of $7.10 \%$ in heating value was also shown by $\mathrm{R} 6$ validating the reciprocal relation between ash content and heating value.

\section{LITERATURE CITED}

1. International Energy Agency, World energy outlook, 2007. http://www.iea.org/publications/freepublications/publication/ weo_2007.pdf

2. Eom, I.Y., Kim, K.H., Kim, J.Y., Lee, S.M., Yeo, H.M. \& Choi, I.G., et al. (2011). Characterization of primary thermal degradation features of lignocellulosic biomass after removal of inorganic metals by diverse solvents., Bioresour. Technol. 102, 3437-44. DOI: 10.1016/j.biortech.2010.10.056.

3. Long, J., Song, H., Jun, X., Sheng, S., Lun-Shi, S. \& Kai, X. et al. (2012). Release characteristics of alkali and alkaline earth metallic species during biomass pyrolysis and steam gasification process, Bioresour. Technol. 116, 278-284. DOI: 10.1016/j.biortech.2012.03.051.

4. Fahmi, R., Bridgwater, A.V., Darvell, L.I., Jones, J.M., Yates, N. \& Thain, S., et al. (2007). The effect of alkali metals on combustion and pyrolysis of Lolium and Festuca grasses, switchgrass and willow, Fuel 86, 1560-1569. DOI: 10.1016/j. fuel.2006.11.030.

5. Fang, X. \& Jia, L. Experimental study on ash fusion characteristics of biomass, Bioresour. Technol. 104, (2012). 769-774. DOI: 10.1016/j.biortech.2011.11.055.

6. Easterly, J.L. \& Burnham, M. (1996). Overview of biomass and waste fuel resources for power production, Biomass and Bioenergy. 10, 79-92. DOI: 10.1016/0961-9534(95)00063-1.

7. Tillman, D.A. (2000). Biomass cofiring: The technology, the experience, the combustion consequences, Biomass and Bioenergy. 19, 365-384. DOI: 10.1016/S0961-9534(00)00049-0.

8. Fahmi, R., Bridgwater, A.V., Donnison, I., Yates, N. \& Jones, J.M. (2008). The effect of lignin and inorganic species in biomass on pyrolysis oil yields, quality and stability, Fuel 87, 1230-1240. DOI: 10.1016/j.fuel.2007.07.026.

9. Davidsson, K.O., Korsgren, J.G. \& Ja, U. (2002). The effects of fuel washing techniques on alkali release from biomass, Fuel 81, 137-142.

10. Liu, X. \& Bi, X.T. (2011). Removal of inorganic constituents from pine barks and switchgrass, Fuel Process. Technol. 92, 1273-1279. DOI: 10.1016/j.fuproc.2011.01.016.

11. Tan, H. \& Wang, S. (2009). Experimental study of the effect of acid-washing pretreatment on biomass pyrolysis, J. Fuel Chem. Technol. 37, 668-672. DOI: 10.1016/S1872-5813(10)60014-X.

12. Lv, D., Xu, M., Liu, X., Zhan, Z., Li, Z. \& Yao, H. (2010). Effect of cellulose, lignin, alkali and alkaline earth metallic 
species on biomass pyrolysis and gasification, Fuel Process. Technol. 91, 903-909. DOI: 10.1016/j.fuproc.2009.09.014.

13. Das, P., Ganesh, A. \& Wangikar, P. (2004), Influence of pretreatment for deashing of sugarcane bagasse on pyrolysis products, Biomass and Bioenergy. 27, 445-457. DOI: 10.1016/j. biombioe.2004.04.002.

14. Vassilev, S.V., Baxter, D., Andersen, L.K., Vassileva, C.G. \& Morgan, T.J. (2012). An overview of the organic and inorganic phase composition of biomass, Fuel 94, 1-33. DOI: 10.1016/j.fuel.2011.09.030.

15. Asadieraghi, M., Mohd, W. \& Wan, A. (2014). Characterization of lignocellulosic biomass thermal degradation and physiochemical structure: Effects of demineralization by diverse acid solutions, Energy Convers. Manag. 82, 71-82. DOI: 10.1016/j.enconman.2014.03.007.

16. Yu, C.T., Chen, W.H., Men, L.C. \& Hwang, W.S. (2009). Microscopic structure features changes of rice straw treated by boiled acid solution, Ind. Crops Prod. 29, 308-315. DOI: 10.1016/j.indcrop.2008.06.005.

17. Jiang, L., Hu, S., Sun, L., Su, S., Xu, K. \& He, L. et al. (2013). Influence of different demineralization treatments on physicochemical structure and thermal degradation of biomass., Bioresour. Technol. 146, 254-60. DOI: 10.1016/j. biortech.2013.07.063.

18. Ounas, A., Aboulkas, A., El Harfi, K., Bacaoui, A. \& Yaacoubi, A. (2011). Pyrolysis of olive residue and sugar cane bagasse: Non-isothermal thermogravimetric kinetic analysis, Bioresour. Technol. 102, 11234-11238. DOI: 10.1016/j.biortech.2011.09.010.

19. Carrillo, M.A., Staggenborg, S.A. \& Pineda, J.A. (2014). Washing sorghum biomass with water to improve its quality for combustion, Fuel 116, 427-431. DOI: 10.1016/j.fuel.2013.08.028. 